\title{
Correction to: A Probabilistic Infection Model for Efficient Trace-Prediction of Disease Outbreaks in Contact Networks
}

William Qian, Sanjukta Bhowmick, Marty O’Neill, Susie Ramisetty-Mikler, and Armin R. Mikler

\author{
Correction to: \\ Chapter "A Probabilistic Infection Model for Efficient \\ Trace-Prediction of Disease Outbreaks in Contact Networks" \\ in: V. V. Krzhizhanovskaya et al. (Eds.): Computational \\ Science - ICCS 2020, LNCS 12137, \\ https://doi.org/10.1007/978-3-030-50371-0_50
}

The original version of this chapter was revised. The first author's first name contained a typo. It has been corrected to "William". 